\title{
Article \\ The Association between Gender and Physical Activity Was Partially Mediated by Social Network Size during COVID-19
}

\author{
Ashley Kuzmik ${ }^{1, *}$, Yin Liu ${ }^{2}$, Yendelela Cuffee ${ }^{3}$, Lan Kong ${ }^{4}$, Christopher N. Sciamanna ${ }^{4}$ and Liza S. Rovniak ${ }^{4}$ \\ 1 College of Nursing, Pennsylvania State University, 306 Nursing Sciences Building, University Park, \\ Philadelphia, PA 16802, USA \\ 2 Department of Human Development and Family Sciences, Utah State University, 2905 Old Main Hill, \\ Logan, UT 84322, USA; yin.liu@usu.edu \\ 3 College of Health Sciences, University of Delaware, 100 Discovery Boulevard, Newark, DE 19713, USA; \\ ylcuffee@udel.edu \\ 4 Departments of Medicine and Public Health Sciences, College of Medicine, Pennsylvania State University, \\ Hershey, PA 17033, USA; luk14@psu.edu (L.K.); csciamanna@pennstatehealth.psu.edu (C.N.S.); \\ lrovniak@pennstatehealth.psu.edu (L.S.R.) \\ * Correspondence: auk536@psu.edu
}

check for updates

Citation: Kuzmik, A.; Liu, Y.; Cuffee,

Y.; Kong, L.; Sciamanna, C.N.; Rovniak, L.S. The Association between Gender and Physical Activity Was Partially Mediated by Social Network Size during COVID-19. Int. J. Environ. Res. Public Health 2022, 19, 2495. https:// doi.org/10.3390/ijerph19052495

Academic Editor: Ellen Glickman

Received: 5 January 2022

Accepted: 18 February 2022

Published: 22 February 2022

Publisher's Note: MDPI stays neutral with regard to jurisdictional claims in published maps and institutional affiliations.

Copyright: (C) 2022 by the authors. Licensee MDPI, Basel, Switzerland. This article is an open access article distributed under the terms and conditions of the Creative Commons Attribution (CC BY) license (https:// creativecommons.org/licenses/by/ $4.0 /)$.

\begin{abstract}
The COVID-19 pandemic has disrupted physical activity, particularly among women. Limited research has explored how social network support may explain gender-based variations in physical activity during COVID-19. The purpose of this study was to examine the mediating role of social networks in the association between gender and physical activity during a pandemic. This cross-sectional survey assessed whether social network characteristics (i.e., in-person social network size, frequency of in-person social network interactions, and online friend network size) mediate the relationship between gender and either past-week or past-year physical activity. Multiple mediation analyses were conducted to determine the indirect effect of gender on physical activity through social networks. Among 205 participants, women $(n=129)$ were significantly less physically active $(\beta=-73.82 ; p=0.02)$ than men $(\mathrm{n}=76)$ and reported significantly more Facebook friends $(\beta=0.30$; $p<0.001)$ than men, which was inversely associated with past-week physical activity $(\beta=-64.49$; $p=0.03$ ). Additionally, the indirect effect of gender on past-week physical activity through Facebook friends was significant $(\beta=-19.13 ; 95 \%$ CI $[-40.45,-2.09])$. Findings suggest that social media sites such as Facebook could be used to encourage physical activity among women during a pandemic.
\end{abstract}

Keywords: COVID-19; women's health; physical activity; social networks

\section{Introduction}

The Physical Activity Guidelines for Americans recommend that adults 18 years or older perform at least $150 \mathrm{~min}$ per week of moderate-intensity exercise or 75 min per week of vigorous-intensity exercise along with at least two days of muscle-strengthening activity to achieve the health benefits associated with an active lifestyle [1]. Women consistently fall behind their male counterparts in their quantity of moderate and vigorous physical activity [2,3]. Pre-COVID-19, a study across 168 countries with almost 2 million participants ( $\geq 18$ years of age) revealed that $32 \%$ of women versus $23 \%$ of men are inactive [4].

Since the onset of the COVID-19 pandemic, women have continued to be less engaged in physical activity than men $[5,6]$. These gender differences in physical activity have largely been attributed to pre-existing low levels of social support [5,7] and heightened demands, such as managing full-time employment together with household tasks and child care [7]. Alongside women's lower levels of activity, COVID-19 restrictions that increase social isolation have exacerbated concerns associated with mental health [7-9]. Specifically, relative to men, women with less physical activity experienced greater mental health concerns (e.g., anxiety) during the pandemic [5]. Women's lower physical activity 
levels have also been linked to increased risk, relative to men, of chronic health conditions, such as cardiovascular disease, cancer and type 2 diabetes [10,11].

Although time constraints and low motivation are common physical activity barriers among women [12], social network support for engaging in physical activity can contribute to reducing these time-related and motivational barriers [13]. The multilevel Social Networks for Activity Promotion (SNAP) model [14] is a framework that demonstrates how physical activity can be influenced by social networks at three different levels: (1) built physical environment (i.e., built, natural, or online settings); (2) social network environment (i.e., population attributes and interaction modes); and (3) social network interactions (social network structure and functions). The SNAP model indicates that both in-person and virtual/online environments may provide either social network support or constraints, which can function, respectively, to promote or inhibit social interactions related to physical activity. Research indicates that greater social network support can influence past-week and past-year physical activity [15].

Previous studies have predominantly emphasized descriptive differences between women's and men's social network structure, defined as the number and frequency of contacts with others who may support or constrain efforts to engage in physical activity [14]. For instance, in pre-pandemic studies investigating social network structure, women tended to have a larger number of networks with a greater diversity of connections (e.g., family, friends, and neighbors), whereas men often had a smaller network size with fewer connections (e.g., co-workers) [16-18]. Additionally, women have more online friends compared to men [19,20], evident in social network sites such as Facebook [20]. To promote physical activity among women during a pandemic, and other periods when physical activity may be particularly compromised, it is important to understand whether modifiable social network characteristics mediate the relationship between gender and physical activity. Such an understanding would inform the design of future in-person and online physical activity interventions.

Although evidence of pre-pandemic associations between gender, social networks, and physical activity exists $[14,17,18,20]$, prior research has not investigated social network characteristics as a mediating pathway linking gender with physical activity. To address this gap, the purpose of this study was to investigate the process by which in-person and online social network structure explains gender-based differences in physical activity. To capture dimensions of social network structure that could be efficiently assessed and confirmed in other independent samples, we used validated self-report measures of social network structure that were described previously [21]. Further, because levels of physical activity fluctuate, both past-year and past-week total minutes were considered to provide a more comprehensive estimate of typical activity levels than either measure alone. Based on prior research $[14,17,18,20]$, we hypothesized that the association between gender and physical activity would be mediated by social network structure.

\section{Materials and Methods}

\subsection{Study Design}

This cross-sectional study was conducted between November 2020 through February 2021, as part of a larger measurement validation study. Ethical approval was obtained by the Pennsylvania State University College of Medicine Institutional Review Board (STUDY00000055). Participants provided informed consent via an online form.

\subsection{Sample}

Participants were required to be: (1) age 18 years or older; (2) comfortable answering written questions in English; (3) "highly physically active", i.e., engage in $150 \mathrm{~min} /$ week or more of regular moderate-vigorous physical activity for at least one year and at least two different modes (types) of physical activity (i.e., strength training and at least one other physical activity mode, such as walking/running), or "highly physically inactive" (60 min/week or less of regular moderate-vigorous physical activity for at least one year) 
based on three brief validated questionnaires [22-25]; (4) residing current address for at least 6 months; and (6) able to provide a valid Amazon Turk Worker ID for future contact.

Exclusion criteria were: (1) pregnancy; (2) inability to walk three city blocks or another medical condition limiting physical activity participation; (3) residence in an institutionalized setting (e.g., retirement home, hospital, prison, mental health facility, etc.) or homeless; (4) plan to relocate within the next month; and (5) provision of Amazon Turk Worker ID that duplicated one received previously. Additionally, participants were recruited from the "most" active US states and from the "least" active US states, based on the proportion of adults in each state meeting aerobic and muscle-strengthening guidelines between 2011 and 2019, as determined by the Behavioral Risk Factor Surveillance System [26]. The "most" active states included Colorado, Hawaii, District of Columbia (DC), Alaska, California, New Mexico, Utah, Vermont, Washington, Wyoming, and Connecticut. The "least" active states included West Virginia, Mississippi, Arkansas, Alabama, Tennessee, Oklahoma, Kentucky, Louisiana, North Dakota, Indiana, and Missouri.

\subsection{Study Procedures}

Participants were recruited through CloudResearch (https:/ / www.cloudresearch.com accessed on 28 February 2021) — an online research platform linked with Amazon Mechanical Turk (MTurk). Specifically, MTurk is an online crowdsourcing platform where researchers post a job assignment called a HIT (Human Intelligence Task), and eligible MTurk workers ( $\geq 18$ years of age) have an opportunity to complete the HIT for compensation. The HIT includes a title and description of the job assignment. It also displays the amount of compensation and time it takes to complete the task. MTurk data exhibit evidence of validity and reliability across various tasks and populations [27-29].

In our study, interested qualified MTurk workers were directed to a study link provided as part of the job assignment (i.e., HIT) that was posted on MTurk's website to be completed by workers for pay. MTurk workers were eligible to participate if they had a minimum 90\% approval rating and at least 100 HITS completed. The study link contained a brief header to describe the study. After reading the online consent information, participants were invited to provide implied informed consent online. Those providing consent were directed to complete the screening form ( 5-10 $\mathrm{min})$ through a REDCap survey link [30]. If participants remained eligible after completing the screening form, they were asked to complete an online social environment questionnaire $(\sim 20 \mathrm{~min})$ and were emailed a REDCap link to this questionnaire using their worker ID within $24 \mathrm{~h}$ of determining eligibility. Participants had up to seven days to complete the questionnaire, and a maximum of three email reminders were sent. Participants were paid $\$ 0.50$ after completing the screening form, and if eligible, $\$ 1.50$ for completing the social environment questionnaire. A unique code was provided to participants to copy and paste into the CloudResearch platform to verify survey completion and obtain compensation for their time.

Attention check questions (blinded to respondents) were included [31]: (1) age in the screening form and year born in survey 1 (should not have more than 1 year difference across measures); and (2) worker ID across all surveys (should be identical across all measures). These attention check questions were naturally embedded in the surveys to validate responses [31] and to differentiate between high-quality and low-quality (inconsistent) responses. A syntax program was written in SPSS to automatically scan all the surveys for responses on the attention check questions (Supplementary Syntax S1). Participants who failed any of the attention check questions were excluded from analyses.

\subsection{Measures}

2.4.1. Independent Variable

The independent variable was gender, a binary variable, with "male" coded as 0 and "female" coded as 1 . 


\subsubsection{Dependent Variables}

Past-Week Physical Activity

The annual National Health Interview Survey (NHIS) is administered by the Centers for Disease Control and Prevention's (CDC) National Center for Health Statistics (NCHS) [22] and evaluates various health topics, including physical activity. The NHIS provides a reliable and valid report of moderate-vigorous physical activity and strength training activity over one week [22,32]. The outcome variable used in analyses was the total number of minutes of moderate-vigorous activity performed over one week.

\section{Past-Year Physical Activity}

The Chasan-Taber Physical Activity Questionnaire (CT-PAQ) is a self-report questionnaire that measures the duration, frequency, and intensity of lifetime recreational physical activities [23,24]. In this study, a subset of this questionnaire was used to evaluate participants' past-year physical activity. The CT-PAQ is highly reliable [23] with concurrent validity between the questionnaire-based activity scores and physical activity log scores [24]. The outcome variable used in the analyses was the number of minutes of moderate-vigorous activity performed over one year.

\subsubsection{Mediator Variables}

\section{Social Network Size and Frequency of Contact}

Social network size and frequency of social contact were measured using the BerkmanSyme Social Network Index (SNI) [21], which has demonstrated adequate test-retest reliability (alpha $=0.64-0.70$ ) and construct validity $[33,34]$. Respondents selected "None", " 1 or 2 ", " $3-5$ ", " $6-9$ ", or " 10 or more" to characterize their social network size, that is, the number of close friends and relatives. These items were subsequently scored as $\leq 2$ friends or $\leq 2$ relatives $=0$ and all other scores $=1$, following previously used procedures [35]. Frequency of social contact (the frequency of monthly contact with close friends or relatives) was similarly scored as $\leq 2$ friends or $\leq 2$ relatives $=0$ and all other scores $=1$ [35].

\section{Number of Facebook Friends}

Facebook friends number was dichotomized using the standard median split approach [36,37], based on evidence that "low" (coded " 0 ") and "high" (coded "1") numbers of friends are associated with differential health outcomes [38,39].

\subsubsection{Control Variables}

The analyses controlled for demographic covariates, including race/ethnicity, education, and high versus low active states. These variables have been previously found to co-vary with gender and physical activity $[4,26,40]$. The COVID-19 seven-day case rate per 100,000 people was included as a continuous covariate to consider the differential impact of pandemic severity across the states measured [41].

\subsection{Data Analysis}

Statistical analyses were performed using SPSS (IBM Corporation, Armonk, NY, USA) and AMOS versions 27 [42] with significance levels at an alpha level of 0.05 . Descriptive statistics were used to assess sample characteristics. Normality of the variables was verified using the Shapiro-Wilk test. Associations between study variables were assessed using Pearson's correlation and presented in a heatmap. Highly correlated variables $(r>0.90)$ indicating multicollinearity and variables that were not correlated with either the independent variable (gender) or dependent variables (past-week or past-year physical activity) were excluded from the mediation analyses [43].

Based on the steps proposed by Preacher and Hayes [44], multiple mediation analyses were conducted (see Figure 1) to assess whether social network characteristics mediate the relationship between gender (independent variable) and physical activity (dependent variable; past-week and past-year minutes of physical activity). To test for the mediation 
effects, two multiple mediation models were performed for each outcome, applying five mediators for each single analysis. Path $C$ represented the main effect of gender as a predictor of physical activity. The A paths $\left(\mathrm{a}_{1}-\mathrm{a}_{5}\right)$ represented the association between gender and the mediator variables (i.e., social network size and frequency of social network interactions). The B paths $\left(b_{1}-b_{5}\right)$ represented the association between the mediator variables and physical activity. Lastly, for path $C$, both gender and mediator variables were entered simultaneously as predictors of physical activity. The following conditions were required to establish mediation: (1) the magnitude of association was statistically significant in A and B paths, and (2) the level of significance of the coefficient in path C was either non-significant (full mediation) or less significant, in which case the total effect between the independent and dependent variable still exists, but in a smaller magnitude (partial mediation). A bootstrap sampling procedure assessed the significance of the total and specific indirect effects for each mediator to estimate mediation [44-46]. Bootstrap estimates were based on 5000 bootstrap samples. The indirect effect was considered statistically significant on the condition that the $95 \%$ confidence interval did not include zero. All mediation analyses controlled for race/ethnicity, education, and state-based physical activity level. Age and marital status were not significantly associated with gender, social networks, or physical activity ( $p>0.05$, respectively), and thus, were not controlled for in the model.

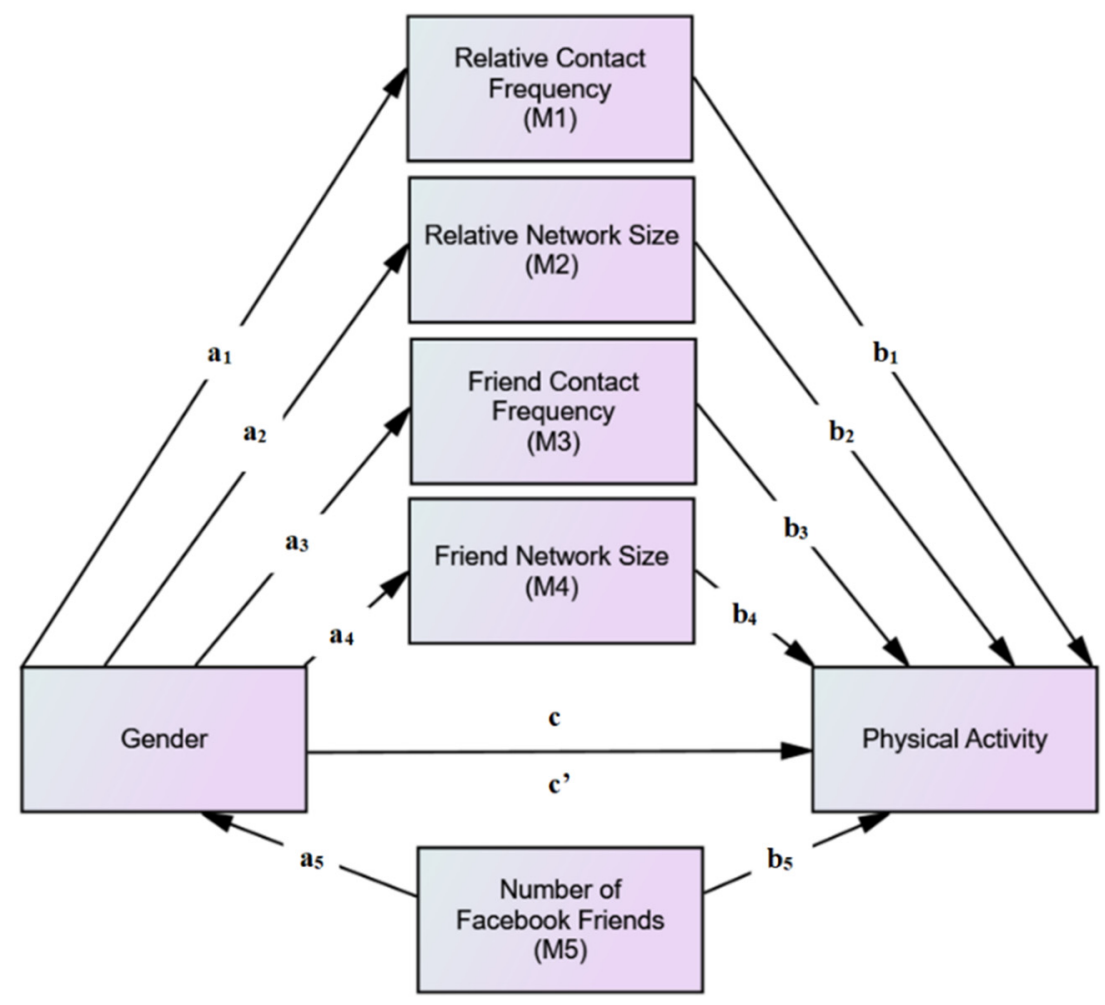

Figure 1. Path diagram of multiple mediation model testing combined effects of proposed mediators of the relationship between gender and physical activity. Paths A: Represent association between gender and mediator variables. Paths B: Represent association between mediator variables and physical activity. Paths C: Represent whether gender and mediator variables together are predictors of physical activity.

\section{Results}

\section{Study Characteristics}

As shown in Table 1 , most of the sample $(\mathrm{N}=205)$ was female $(62.93 \%)$, non-Hispanic $(96.59 \%)$, white $(85.36 \%)$, and had a mean age of $40.98 \pm 12.89$ years. Participants reported a range of self-rated health statuses, including excellent health $(18.54 \%)$, very good health (35.61\%), fair health (14.63\%), and poor health (1.46\%). Among the participants, $46.83 \%$ 
were married, 35.63\% had a 4-year college degree, $25.85 \%$ earned an income between $\$ 30,000$ and $\$ 49,999$, and $75.12 \%$ lived in a single-family house. The mean number of Facebook friends was $255.81 \pm 375.37$. Participants spent on average $168.79 \pm 220.23 \mathrm{~min}$ in moderate-vigorous physical activity per week and $232.27 \pm 350.64$ min (per week) in moderate-vigorous activity over the past year.

Table 1. Characteristics of the study sample $(\mathrm{N}=205)$.

\begin{tabular}{|c|c|c|}
\hline & Variable & n (\%) \\
\hline \multirow{2}{*}{ Gender $^{a}$} & Female & $129(62.93)$ \\
\hline & Male & $76(37.07)$ \\
\hline \multirow{2}{*}{ Ethnicity ${ }^{b}$} & Not Hispanic or Latino & $198(96.59)$ \\
\hline & Hispanic or Latino & $7(3.41)$ \\
\hline \multirow{4}{*}{ Race $^{c}$} & American Indian or Alaskan Native & $2(.98)$ \\
\hline & Asian & $14(6.83)$ \\
\hline & Black or African American & $14(6.83)$ \\
\hline & White & $175(85.36)$ \\
\hline \multirow{6}{*}{ Education $^{\mathrm{d}}$} & High school or GED & $25(12.19)$ \\
\hline & Some college & $40(19.51)$ \\
\hline & 2-year college degree & $29(14.15)$ \\
\hline & 4-year college degree & $71(34.63)$ \\
\hline & Master's degree & $31(15.12)$ \\
\hline & Doctoral degree & $9(4.39)$ \\
\hline \multirow{6}{*}{ Marital status ${ }^{\mathrm{e}}$} & Single and never married & $66(32.20)$ \\
\hline & Married & $96(46.83)$ \\
\hline & Divorced & $22(10.73)$ \\
\hline & Separated & $4(1.95)$ \\
\hline & Widowed & $2(.98)$ \\
\hline & Living with partner & $15(7.32)$ \\
\hline \multirow{7}{*}{ Income $^{f}$} & Less than $\$ 30,000$ & $46(22.44)$ \\
\hline & $\$ 30,000-\$ 49,999$ & $53(25.85)$ \\
\hline & $\$ 50,000-\$ 69,999$ & $40(19.51)$ \\
\hline & $\$ 70,000-\$ 89,999$ & $25(12.19)$ \\
\hline & $\$ 90,000-\$ 109,999$ & $18(8.78)$ \\
\hline & $\$ 110,000-\$ 149,999$ & $16(7.80)$ \\
\hline & $\$ 150,000$ or greater & $7(3.41)$ \\
\hline \multirow{7}{*}{ Residence $\mathrm{g}$} & Single-family house & $154(75.12)$ \\
\hline & Multi-family house & $3(1.46)$ \\
\hline & Apartment & $25(12.20)$ \\
\hline & Condominium & $4(1.95)$ \\
\hline & Townhouse & $10(4.88)$ \\
\hline & Duplex & $6(2.93)$ \\
\hline & Other & $3(1.46)$ \\
\hline
\end{tabular}


Table 1. Cont.

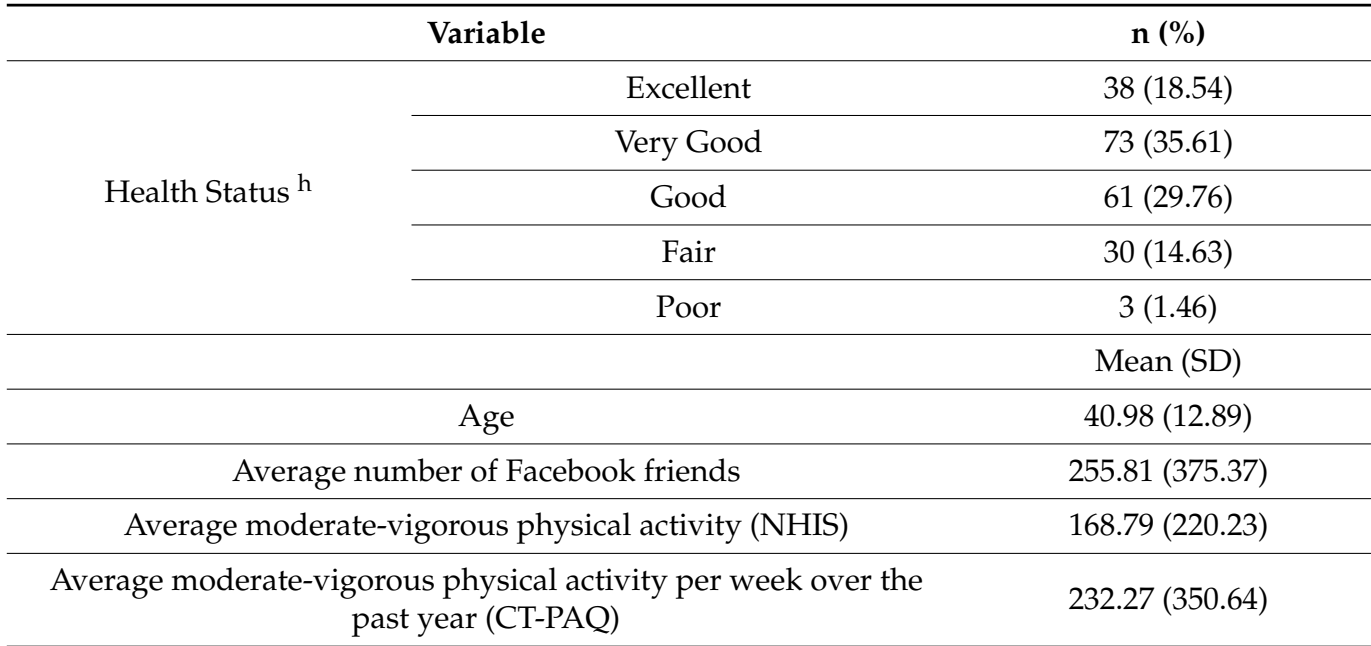

Note: ${ }^{\mathrm{a}}$ Gender was coded as $0=$ male and $1=$ female; $^{\mathrm{b}}$ Ethnicity was coded as $0=$ Not Hispanic or Latino and $1=$ Hispanic or Latino; ${ }^{\mathrm{c}}$ Race was coded as $1=$ American Indian or Alaskan Native and $4=$ White; ${ }^{\mathrm{d}}$ Education was coded as $1=$ High school or GED and $6=$ Doctoral degree; ${ }^{\mathrm{e}}$ Marital status was coded as $1=$ Single and never married and $6=$ Living with partner; ${ }^{\mathrm{f}}$ Income was coded as $1=$ Less than $\$ 30,000$ and $7=\$ 150,000$ or greater;

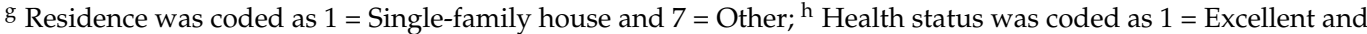
$5=$ Poor.

Figure 2 shows that the highest correlation among the predictor variables was 0.58 , suggesting that the shared variance between each variable was sufficiently small that each variable could contribute to the overall analysis. Relative network size and relative contact frequency were not associated with gender or physical activity and therefore excluded as mediators from the models. Additionally, Facebook friends number was not associated with past-year physical activity and was not included in the mediation analysis.

\begin{tabular}{|c|c|c|c|c|c|c|c|c|}
\hline & Gender & $\begin{array}{c}\text { Friend } \\
\text { Network } \\
\text { Size }\end{array}$ & $\begin{array}{c}\text { Friend } \\
\text { Contact } \\
\text { Frequency }\end{array}$ & $\begin{array}{c}\text { Relative } \\
\text { Network } \\
\text { Size }\end{array}$ & $\begin{array}{c}\text { Relative } \\
\text { Contact } \\
\text { Frequency }\end{array}$ & $\begin{array}{c}\text { Number of } \\
\text { Facebook } \\
\text { Friends }\end{array}$ & $\begin{array}{c}\text { Past-Week } \\
\text { Physical } \\
\text { Activity }\end{array}$ & $\begin{array}{c}\text { Past-Year } \\
\text { Physical } \\
\text { Activity }\end{array}$ \\
\hline Gender & - & 0.05 & 0.04 & 0.05 & 0.07 & $0.29^{* *}$ & $-0.15^{*}$ & $-0.20^{* *}$ \\
\hline $\begin{array}{c}\text { Friend } \\
\text { Network } \\
\text { Size }\end{array}$ & - & - & $0.54^{* * *}$ & $0.28^{* * *}$ & 0.13 & 0.14 & $0.20^{* *}$ & $0.21^{* *}$ \\
\hline $\begin{array}{c}\text { Friend } \\
\text { Contact } \\
\text { Frequency }\end{array}$ & - & - & - & $0.22^{* *}$ & 0.16 & 0.08 & 0.18 & 0.19 \\
\hline $\begin{array}{c}\text { Relative } \\
\text { Network } \\
\text { Size }\end{array}$ & - & - & - & - & $0.58^{* *}$ & 0.02 & 0.01 & 0.02 \\
\hline $\begin{array}{c}\text { Relative } \\
\text { Contact } \\
\text { Frequency }\end{array}$ & - & - & - & - & - & -0.04 & 0.03 & 0.11 \\
\hline $\begin{array}{c}\text { Number of } \\
\text { Facebook } \\
\text { Friends }\end{array}$ & - & - & - & - & - & - & $-0.14^{*}$ & -0.12 \\
\hline $\begin{array}{c}\text { Past-Week } \\
\text { Physical } \\
\text { Activity }\end{array}$ & - & - & - & - & - & - & - & $0.86^{* * *}$ \\
\hline $\begin{array}{c}\text { Past-Year } \\
\text { Physical } \\
\text { Activity }\end{array}$ & - & - & - & - & - & - & - & - \\
\hline
\end{tabular}

Figure 2. Heatmap of Pearson correlation coefficients between the study variables. Notes: ${ }^{*} p \leq 0.05$; ** $p \leq 0.01$.

Figure 3 shows that women with more Facebook friends perform more minutes of past-week physical activity compared to men. For example, a woman with 1800 Facebook friends performed 38.33 more minutes of physical activity per week, on average, than a man with 1800 Facebook friends. 


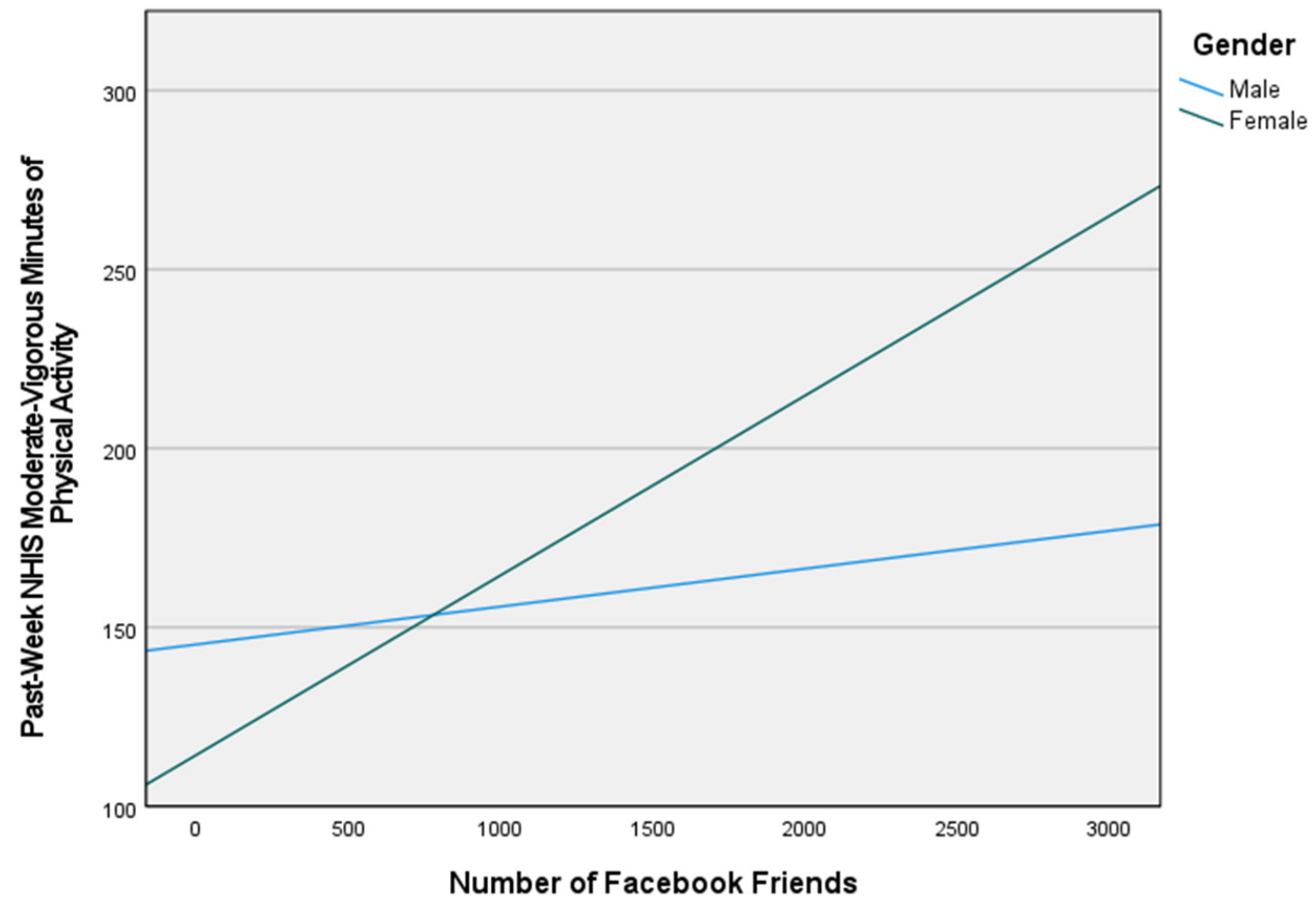

Figure 3. Graphic representation of the number of Facebook friends by gender on NHIS moderatevigorous minutes of physical activity. Notes: NHIS Moderate-Vigorous Physical Activity.

As shown in Figure 4, the results of the mediation analysis revealed there was a significant total effect of gender on past-week physical activity $(\beta=-73.82 ; p=0.02)$, and when Facebook friends number (mediating variable) was added into the model, the association between gender and past-week physical activity became non-significant $(\beta=-48.94 ; p=0.12)$. The model revealed that women had significantly more Facebook friends than men $(\beta=0.30 ; p<0.001)$, and Facebook friends number was significantly and inversely related to past-week physical activity $(\beta=-64.49 ; p=0.03)$. Furthermore, as shown in Table 2, the indirect effect of Facebook friends number between gender and past-week physical activity was significant, but the indirect effects were not significant for friend network size and friend contact frequency. No significant indirect effects were found for friend network size and friend contact frequency between gender and past-year physical activity.

Table 2. Indirect effects of mediator variables of gender on past-week physical activity.

\begin{tabular}{|c|c|c|c|c|}
\hline \multirow{3}{*}{ Pathway } & \multicolumn{4}{|c|}{ Indirect Effect } \\
\hline & \multirow{2}{*}{$\beta$} & \multirow{2}{*}{ SE } & \multicolumn{2}{|c|}{ Bootstrapped 95\% CI } \\
\hline & & & Lower & Upper \\
\hline Gender-All Mediator Variables_-Physical Activity & -24.88 & 12.70 & -50.29 & -4.07 \\
\hline Gender-Friend Network Size—Physical Activity & -3.39 & 6.00 & -18.24 & 5.90 \\
\hline Gender-Friend Contact Frequency_-Physical Activity & -2.36 & 5.28 & -15.66 & 6.63 \\
\hline Gender-Facebook Friends_-Physical Activity & -19.13 & 9.71 & -40.45 & -2.09 \\
\hline
\end{tabular}

Notes: Dependent Variable: NHIS Moderate-Vigorous Minutes (past-week physical activity). 


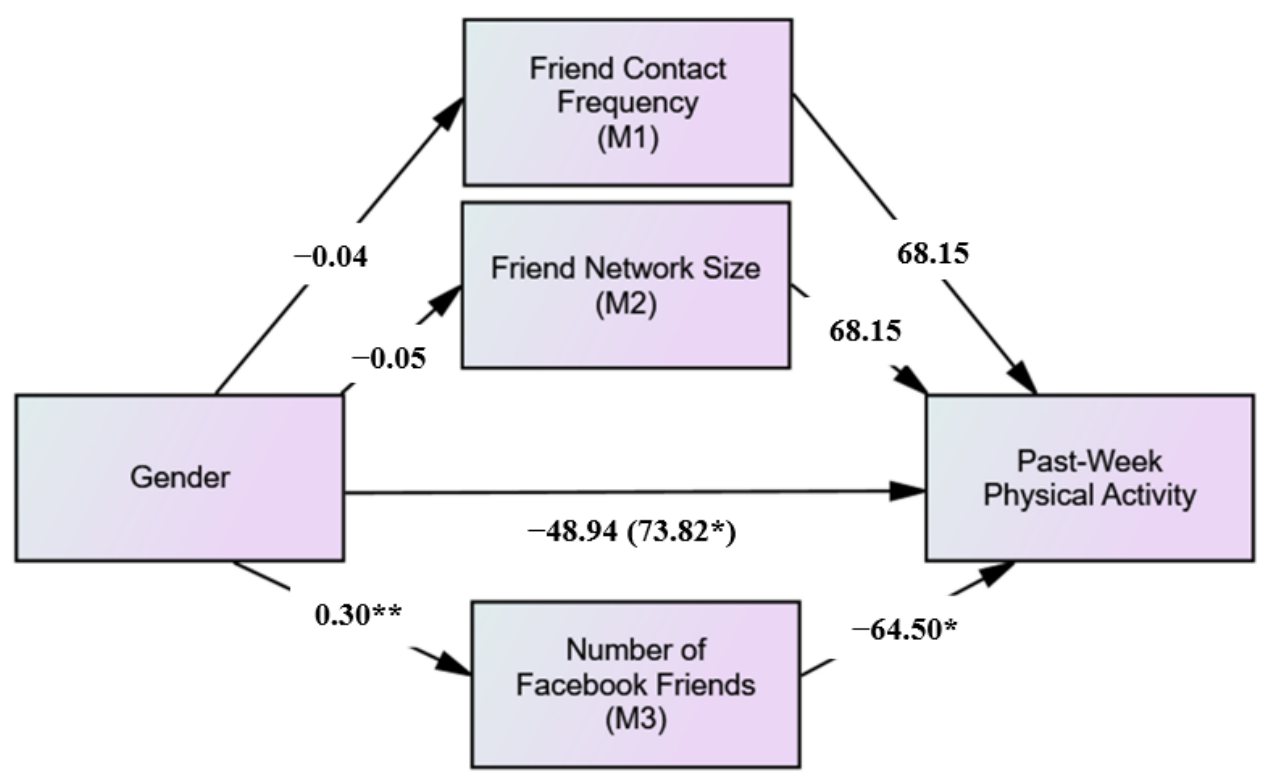

Figure 4. Mediation effects of number of Facebook friends on the relationship between gender and past-week physical activity. Notes: ${ }^{*} p<0.05,{ }^{* *} p<0.001$; Total effect (C path) in parentheses.

\section{Discussion}

The purpose of this study was to examine the contribution of in-person and online social network structure during COVID-19 to explain gender-based disparities in physical activity. Although previous studies have descriptively summarized gender differences and social network characteristics in relation to physical activity during the COVID-19 pandemic $[5,7]$, none have used mediation analysis to quantify the indirect effect of gender on physical activity through social networks.

Based on our mediation analyses, we found that the association between being female and having lower past-week physical activity was partially mediated by a key feature of online social network structure, i.e., the number of Facebook friends. The non-significant effects of friend network size and friend contact frequency (in-person) between gender and both past-week and past-year physical activity suggest that online social network characteristics may be more salient than in-person social networks for influencing women's physical activity. Consistent with these findings, pre-pandemic studies found that women were more likely to use Facebook to maintain contact with a variety of friends [16,47] and to have more Facebook friends then men [18]. On the other hand, men may be more willing to seek new Facebook friends [16] and to have more intimate discussions with their new Facebook friends [48]. These gender-based variations in social network characteristics may influence gender disparities in physical activity during a pandemic. It is important to note that a higher number of Facebook friends was significantly inversely associated with lower levels of past-week physical activity. It is possible that the inverse relationship between Facebook friends and physical activity may be explained by the fact that women spend more time on Facebook then men $[20,49]$ and are more likely to be habituated to Facebook then men [20]. Thus, as women try to maintain a large network of Facebook friends, they may have less time available to exercise due to the extra time spent on Facebook relative to men.

The results of this study are consistent with other research supporting the use of media technologies, such as social media platforms, to encourage physical activity during the COVID-19 pandemic [50,51]. Our findings add new understanding on using online social networks (i.e., Facebook friends) to promote physical activity among women during a pandemic. Future research should further examine the use of media technology via other social networking sites (e.g., Twitter) to help encourage physical activity among women during a pandemic or other natural disasters. 


\section{Implications}

Findings suggest that social media sites such as Facebook could be used to facilitate and encourage physical activity among women during a pandemic. Specifically, pre-pandemic, women's high number of Facebook friends were used to support online workouts, to motivate and encourage women to exercise, and to serve as accountability partners through observing/tracking group-based activity via mobile apps [14,52]. Thus, while women's current Facebook networks may emphasize sedentary behaviors, it may be possible to harness existing Facebook networks to help women transition to more active lifestyles during a pandemic.

Because this study took place during a pandemic, it is unclear if findings would be replicated in non-pandemic times, as there is a lack of pre-pandemic data on the mediating effect of social networks in explaining gender-based differences in physical activity. However, as COVID-19 becomes endemic, there are likely to be periods with higher and lower rates of COVID [53], and these natural variations in COVID rates will provide further opportunities to test the limits of generalizability. The current study, which used reproducible measures via a popular online data collection platform, can serve as an initial step in clarifying the influence of social networks on gender disparities in physical activity and may help set the stage for further confirmation in other independent samples.

\section{Limitations}

This cross-sectional study included a relatively small, U.S. convenience sample of mostly white, healthier adults, which limits causal inferences and generalizability to more diverse populations. This study only included male and female participants; thus, we did not consider non-binary gender status in our analysis. Additionally, other factors, such as mental illness (e.g., anxiety) [5] and sleep quality [54] that could influence social networks and physical activity during a pandemic, were not examined, which may have affected the results. The study also did not assess multiple types of online social network influences that may impact physical activity, such as use of Instagram, Twitter, LinkedIn, or other social networking sites. Furthermore, participants' frequency of interacting with their Facebook friends, and the characteristics of those interactions, along with overall time spent on social media, were not captured. Thus, the actual mechanism by which Facebook friends influence physical activity still warrants further investigation. Moreover, mediator analyses emphasized a single dimension of the social environment (i.e., network size), and our analyses did not incorporate other potential mediator variables, such as extraversion [55] or enjoyment [56] of physical activity. Furthermore, although the pastweek and past-year physical activity questionnaires exhibit evidence of reliability and validity [22-24,32], it is possible that responses to these questionnaires may be subject to recall biases or measurement error. Finally, we did not include a control group to assess pre-pandemic activity levels and social network characteristics.

\section{Conclusions}

Despite these limitations, our findings contribute to understanding the observed gender gap in physical activity during a pandemic. The identification of Facebook friends number as a mediator between gender and physical activity suggests that this social network characteristic may warrant further examination to help women adopt more active lifestyles during a pandemic. Future studies should explore how the online social media environment can be harnessed across the lifespan, and among diverse communities, to address gender inequality in physical activity during pandemic times and other situations associated with social isolation.

Supplementary Materials: The following supporting information can be downloaded at: https: / / www.mdpi.com/article/10.3390/ijerph19052495/s1, Syntax S1: SPSS syntax that was written to screen for attention check questions. 
Author Contributions: Conceptualization, A.K. and L.S.R.; Formal analysis, A.K., Y.L. and L.K.; Investigation, A.K.; Methodology, A.K. and L.S.R.; Data interpretation, A.K., Y.L., Y.C., L.K., C.N.S. and L.S.R.; Writing—original draft, A.K.; Writing—review and editing, A.K., Y.L., Y.C., L.K., C.N.S. and L.S.R. All authors have read and agreed to the published version of the manuscript.

Funding: This research was supported by developmental research funds from the Pennsylvania State University College of Medicine. The study received no external funding.

Institutional Review Board Statement: This study was conducted according to the guidelines of the Declaration of Helsinki, and approved by the Institutional Review Board of the Pennsylvania State University College of Medicine (STUDY00000055, 26 October 2020).

Informed Consent Statement: Informed consent was obtained from all subjects involved in the study.

Data Availability Statement: The data presented in this study are available on request from the corresponding author.

Conflicts of Interest: The authors declare no conflict of interest.

$\begin{array}{ll}\text { Abbreviations } \\ \text { CDC } & \text { Centers for Disease Control and Prevention } \\ \text { CI } & \text { Confidence Interval } \\ \text { CT-PAQ } & \text { Chasan-Taber Physical Activity Questionnaire } \\ \text { HIT } & \text { Human Intelligence Task } \\ \text { ID } & \text { Identification } \\ \text { MTurk } & \text { Mechanical Turk } \\ \text { NHIS } & \text { National Interview Survey } \\ \text { SD } & \text { Standard Deviation } \\ \text { SNAP } & \text { Social Networks for Activity Promotion } \\ \text { SNI } & \text { Berkman-Syme Social Network Index } \\ \text { US } & \text { United States }\end{array}$

\section{References}

1. Piercy, K.L.; Troiano, R.P.; Ballard, R.M.; Carlson, S.A.; Fulton, J.E.; Galuska, D.A.; George, S.M.; Olson, R.D. The Physical Activity Guidelines for Americans. JAMA 2018, 320, 2020-2028. [CrossRef] [PubMed]

2. Armstrong, S.; Wong, C.A.; Perrin, E.; Page, S.; Sibley, L.; Skinner, A. Association of Physical Activity With Income, Race/Ethnicity, and Sex Among Adolescents and Young Adults in the United States: Findings From the National Health and Nutrition Examination Survey, 2007-2016. JAMA Pediatr. 2018, 172, 732-740. [CrossRef]

3. Sallis, J.; Bull, F.; Guthold, R.; Heath, G.W.; Inoue, S.; Kelly, P.; Oyeyemi, A.L.; Perez, L.G.; Richards, J.; Hallal, P.C. Progress in physical activity over the Olympic quadrennium. Lancet 2016, 388, 1325-1336. [CrossRef]

4. Guthold, R.; Stevens, G.A.; Riley, L.M.; Bull, F.C. Worldwide trends in insufficient physical activity from 2001 to 2016 : A pooled analysis of 358 population-based surveys with 1.9 million participants. Lancet Glob. Health 2018, 6, e1077-e1086. [CrossRef]

5. Nienhuis, C.P.; Lesser, I.A. The Impact of COVID-19 on Women's Physical Activity Behavior and Mental Well-Being. Int. J. Environ. Res. Public Health 2020, 17, 9036. [CrossRef]

6. Qin, F.; Song, Y.; Nassis, G.P.; Zhao, L.; Dong, Y.; Zhao, C.; Feng, Y.; Zhao, J. Physical Activity, Screen Time, and Emotional Well-Being during the 2019 Novel Coronavirus Outbreak in China. Int. J. Environ. Res. Public Health 2020, 17, 5170. [CrossRef] [PubMed]

7. Forsyth, J.J.; Makay, L.; Riley, V. Perceptions of Physical Activity Changes Due to COVID-19 Restrictions Among Women in the United Kingdom. Women Sport Phys. Act. J. 2021, 29, 117-126. [CrossRef]

8. Pieh, C.; Budimir, S.; Probst, T. The effect of age, gender, income, work, and physical activity on mental health during coronavirus disease (COVID-19) lockdown in Austria. J. Psychosom. Res. 2020, 136, 110186. [CrossRef]

9. Maugeri, G.; Castrogiovanni, P.; Battaglia, G.; Pippi, R.; D'Agata, V.; Palma, A.; Di Rosa, M.; Musumeci, G. The impact of physical activity on psychological health during Covid-19 pandemic in Italy. Heliyon 2020, 6, e04315. [CrossRef]

10. Aune, D.; Norat, T.; Leitzmann, M.; Tonstad, S.; Vatten, L.J. Physical activity and the risk of type 2 diabetes: A systematic review and dose-response meta-analysis. Eur. J. Epidemiol. 2015, 30, 529-542. [CrossRef]

11. Chomistek, A.K.; Cook, N.R.; Rimm, E.B.; Ridker, P.M.; Buring, J.E.; Lee, I.-M. Physical Activity and Incident Cardiovascular Disease in Women: Is the Relation Modified by Level of Global Cardiovascular Risk? J. Am. Heart Assoc. 2018, 7, e008234. [CrossRef]

12. Moreno, J.P.; Johnston, C.A. Barriers to Physical Activity in Women. Am. J. Lifestyle Med. 2014, 8, 164-166. [CrossRef] 
13. Edwards, E.S.; Sackett, S.C. Psychosocial Variables Related to Why Women are Less Active than Men and Related Health Implications. Clin. Med. Insights Womens Health 2016, 9, 47-56. [CrossRef]

14. Rovniak, L.S.; Sallis, J.F.; Kraschnewski, J.L.; Sciamanna, C.N.; Kiser, E.J.; Ray, C.A.; Chinchilli, V.M.; Ding, D.; Matthews, S.A.; Bopp, M.; et al. Engineering online and in-person social networks to sustain physical activity: Application of a conceptual model. BMC Public Health 2013, 13, 1-15. [CrossRef]

15. Scarapicchia, T.M.F.; Amireault, S.; Faulkner, G.; Sabiston, C.M. Social support and physical activity participation among healthy adults: A systematic review of prospective studies. Int. Rev. Sport Exerc. Psychol. 2017, 10, 50-83. [CrossRef]

16. Haq, A.u.; Chand, S. Exploratory Study of the Pattern and Motives of Facebook Usage among University Students. J. Stat. 2014, $21,118-127$.

17. McDonald, S.; Mair, C.A. Social Capital Across the Life Course: Age and Gendered Patterns of Network Resources1. Sociol. Forum 2010, 25, 335-359. [CrossRef]

18. McLaughlin, D.; Vagenas, D.; Pachana, N.A.; Begum, N.; Dobson, A. Gender Differences in Social Network Size and Satisfaction in Adults in Their 70s. J. Health Psychol. 2010, 15, 671-679. [CrossRef]

19. McAndrew, F.T.; Jeong, H.S. Who does what on Facebook? Age, sex, and relationship status as predictors of Facebook use. Comput. Hum. Behav. 2012, 28, 2359-2365. [CrossRef]

20. Thompson, S.H.; Lougheed, E. Frazzled by Facebook? An Exploratory Study of Gender Differences in Social Network Communication among Undergraduate Men and Women. Coll. Stud. J. 2012, 46, 88-98.

21. Berkman, L.F.; Syme, S.L. Social networks, host resistance, and mortality: A nine-year follow-up study of Alameda County residents. Am. J. Epidemiol. 1979, 109, 186-204. [CrossRef] [PubMed]

22. CDC National Health Interview Survey. Available online: https://www.cdc.gov/nchs/nhis/index.htm (accessed on 15 August 2020).

23. Chasan-Taber, L.; Erickson, J.B.; McBride, J.W.; Nasca, P.C.; Chasan-Taber, S.; Freedson, P.S. Reproducibility of a Self-administered Lifetime Physical Activity Questionnaire among Female College Alumnae. Am. J. Epidemiol. 2002, 155, 282-291. [CrossRef] [PubMed]

24. Chasan-Taber, L.; Erickson, J.B.; Nasca, P.C.; Chasan-Taber, S.; Freedson, P.S. Validity and reproducibility of a physical activity questionnaire in women. Med. Sci. Sports Exerc. 2002, 34, 987-992. [CrossRef] [PubMed]

25. Kiernan, M.; Moore, S.D.; Schoffman, D.E.; Lee, K.; King, A.C.; Taylor, C.B.; Kiernan, N.E.; Perri, M.G. Social support for healthy behaviors: Scale psychometrics and prediction of weight loss among women in a behavioral program. Obesity 2012, 20, 756-764. [CrossRef]

26. CDC BRFSS Prevalence \& Trends Data: Home IDPH ICDC. Available online: https://www.cdc.gov/brfss/brfssprevalence/ index.html (accessed on 2 September 2020).

27. Litman, L.; Robinson, J.; Rosenzweig, C. The relationship between motivation, monetary compensation, and data quality among US- and India-based workers on Mechanical Turk. Behav. Res. Methods 2015, 47, 519-528. [CrossRef]

28. Mortensen, K.; Hughes, T.L. Comparing Amazon's Mechanical Turk Platform to Conventional Data Collection Methods in the Health and Medical Research Literature. J. Gen. Intern. Med. 2018, 33, 533-538. [CrossRef]

29. Shapiro, D.N.; Chandler, J.; Mueller, P.A. Using Mechanical Turk to Study Clinical Populations. Clin. Psychol. Sci. 2013, 1, 213-220. [CrossRef]

30. Harris, P.A.; Taylor, R.; Thielke, R.; Payne, J.; Gonzalez, N.; Conde, J.G. Research electronic data capture (REDCap)—A metadatadriven methodology and workflow process for providing translational research informatics support. J. Biomed. Inform. 2009, 42, 377-381. [CrossRef]

31. Sheehan, K.B. Crowdsourcing research: Data collection with Amazon's Mechanical Turk. Commun. Monogr. 2018, 85, 140-156. [CrossRef]

32. Sun, F.; Norman, I.J.; While, A.E. Physical activity in older people: A systematic review. BMC Public Health 2013, 13, 449. [CrossRef]

33. Cohen, S. Social relationships and health. Am. Psychol. 2004, 59, 676-684. [CrossRef]

34. Trudel-Fitzgerald, C.; Chen, Y.; Singh, A.; Okereke, O.I.; Kubzansky, L.D. Psychiatric, Psychological, and Social Determinants of Health in the Nurses' Health Study Cohorts. Am. J. Public Health 2016, 106, 1644-1649. [CrossRef]

35. Loucks, E.B.; Sullivan, L.M.; D’Agostino, R.B.; Larson, M.G.; Berkman, L.F.; Benjamin, E.J. Social networks and inflammatory markers in the Framingham Heart Study. J. Biosoc. Sci. 2006, 38, 835-842. [CrossRef]

36. Iacobucci, D.; Posavac, S.S.; Kardes, F.R.; Schneider, M.J.; Popovich, D.L. Toward a more nuanced understanding of the statistical properties of a median split. J. Consum. Psychol. 2015, 25, 652-665. [CrossRef]

37. Iacobucci, D.; Posavac, S.S.; Kardes, F.R.; Schneider, M.J.; Popovich, D.L. The median split: Robust, refined, and revived. J. Consum. Psychol. 2015, 25, 690-704. [CrossRef]

38. Maier, C.; Laumer, S.; Eckhardt, A.; Weitzel, T. Giving too much social support: Social overload on social networking sites. Eur. J. Inf. Syst. 2015, 24, 447-464. [CrossRef]

39. Nabi, R.L.; Prestin, A.; So, J. Facebook friends with (health) benefits? Exploring social network site use and perceptions of social support, stress, and well-being. Cyberpsychol. Behav. Soc. Netw. 2013, 16, 721-727. [CrossRef] 
40. Scholes, S.; Bann, D. Education-related disparities in reported physical activity during leisure-time, active transportation, and work among US adults: Repeated cross-sectional analysis from the National Health and Nutrition Examination Surveys, 2007 to 2016. BMC Public Health 2018, 18, 1-10. [CrossRef]

41. CDC COVID Data Tracker. Available online: https:/ / covid.cdc.gov/covid-data-tracker (accessed on 22 July 2021).

42. IBM Corp. IBM SPSS Statistics for Windows, Version; IBM Corp: Armonk, NY, USA, 2020.

43. Tabachnick, B.G.; Fidell, L.S. Using Multivariate Statistics, 6th ed.; Pearson: Boston, MA, USA, 2013; ISBN 0-321-05677-9.

44. Preacher, K.J.; Hayes, A.F. Asymptotic and resampling strategies for assessing and comparing indirect effects in multiple mediator models. Behav. Res. Methods 2008, 40, 879-891. [CrossRef]

45. Preacher, K.J.; Hayes, A.F. SPSS and SAS procedures for estimating indirect effects in simple mediation models. Behav. Res. Methods Instrum. Comput. 2004, 36, 717-731. [CrossRef]

46. Shrout, P.E.; Bolger, N. Mediation in experimental and nonexperimental studies: New procedures and recommendations. Psychol. Methods 2002, 7, 422-445. [CrossRef]

47. Mazman, S.G.; Usluel, Y.K. Gender Differences in Using Social Networks. Undefined 2011, 10, $133-139$.

48. Sheldon, P. Examining Gender Differences in Self-disclosure on Facebook Versus Face-to-Face. J. Soc. Media Soc. 2013, 1, 88-105.

49. Denti, L.; Barbopuolos, I.; Nilsson, I.; Holmberg, L.; Thulin, M.; Wendeblad, M.; Andén, L.; Davidsson, E. Sweden's largest Facebook study. Gothenbg. Res. Inst. 2012, 3, 1-38.

50. AlMarzooqi, M.A. Physical Activity and Attitudes Toward Social Media Use of Active Individuals During the COVID-19 Pandemic in Saudi Arabia: Cross-Sectional Survey. Front. Psychol. 2021, 12, 707921. [CrossRef] [PubMed]

51. Goodyear, V.A.; Boardley, I.; Chiou, S.-Y.; Fenton, S.A.M.; Makopoulou, K.; Stathi, A.; Wallis, G.A.; Veldhuijzen van Zanten, J.J.C.S.; Thompson, J.L. Social media use informing behaviours related to physical activity, diet and quality of life during COVID-19: A mixed methods study. BMC Public Health 2021, 21, 1333. [CrossRef]

52. Rovniak, L.S.; Kong, L.; Hovell, M.F.; Ding, D.; Sallis, J.F.; Ray, C.A.; Kraschnewski, J.L.; Matthews, S.A.; Kiser, E.; Chinchilli, V.M.; et al. Engineering Online and In-person Social Networks for Physical Activity: A Randomized Trial. Ann. Behav. Med. Publ. Soc. Behav. Med. 2016, 50, 885-897. [CrossRef]

53. Lavine, J.S.; Bjornstad, O.N.; Antia, R. Immunological characteristics govern the transition of COVID-19 to endemicity. Science 2021, 371, 741-745. [CrossRef] [PubMed]

54. Vargas, I.; Howie, E.K.; Muench, A.; Perlis, M.L. Measuring the Effects of Social Isolation and Dissatisfaction on Depressive Symptoms during the COVID-19 Pandemic: The Moderating Role of Sleep and Physical Activity. Brain Sci. 2021, $11,1449$. [CrossRef] [PubMed]

55. Lepri, B.; Staiano, J.; Shmueli, E.; Pianesi, F.; Pentland, A. The Role of Personality in Shaping Social Networks and Mediating Behavioral Change. User Model. User-Adapt. Interact. 2016, 26, 143-175. [CrossRef]

56. Chen, C.; Finne, E.; Kopp, A.; Jekauc, D. Can Positive Affective Variables Mediate Intervention Effects on Physical Activity? A Systematic Review and Meta-Analysis. Front. Psychol. 2020, 11, 2907. [CrossRef] 